\title{
News, Notes and Queries \\ UNIVERSITY OF EDINBURGh, FaCULTY OF MEDICINE \\ Wellcome Medal and Prize in the History of Medicine
}

The above medal and prize of $£ 25$ will be awarded in July 1967 for the best essay on 'Changing Concepts of the Causes of Congenital Deformities'. The competition is open to medical students and to recent graduates in medicine and surgery of the University of Edinburgh. Further details may be obtained from the Dean of the Faculty of Medicine.

This medal and prize was instituted by Sir Henry Wellcome personally in 1912. The 1966 award was made to Mr. Brian Covell, B.Sc., for his essay on 'The Origin and Development of the Hospital in British Medical Practice'.

\section{Faculty of the History of Medicine and Pharmacy (WORSŸIIPFUL SOCIETY OF APOTHECARIES OF LONDON) Maccabaean Prize and Medal}

Entries for the 1967 Maccabaean Prize of 25 guineas and a bronze medal are now invited for an essay of 5,000 to 7,000 words on some aspect of the history of medicine or pharmacy. Intending candidates, who must be under thirty years of age on 15 March, 1967, may apply for further particulars to the Hon. Secretary of the Faculty (Dr. F. N. L. Poynter, The Wellcome Historical Medical Library, The Wellcome Building, Euston Road, London, N.W.1.)

\section{BRITISH SOCIETY FOR THE History OF MEDICINE}

The Sixth British Congress on the History of Medicine will be held in the University of Sussex (Brighton) from the evening of Wednesday 6th to 12.30 p.m. on Saturday 9th September 1967. The theme of the congress will be Medicine in the 1860s. The fee for the meeting, which includes accommodation and full board in the university for three nights, and the Congress Dinner on Friday 8 September, is ten guineas, plus a registration fee of $£ 2$ ( $£ 15 s$. 0d. for Members of the British Society for the History of Medicine). Further details and application forms are available from: Dr. F. N. L. Poynter (Hon. Sec.), Wellcome Historical Medical Museum and Library, The Wellcome Building, Euston Road, London, N. W. 1. 